\title{
Adapted Reuse of Cultural Heritage \& Atmosphere-Making in Lingnan Impression Park
}

\author{
Yifeng WEN ${ }^{\mathrm{a}, 1}$ \\ ${ }^{a}$ School of Architecture and Urban Planning, Guangzhou University, Guangzhou, \\ 510006, China
}

\begin{abstract}
In this article Lingnan Impression Park is taken as case study to research on integrated strategies of cultural heritage conservation with the purpose of its adapted reuse. In process exploitation, a combined strategy reusing architecture heritage is adopted, to produce an atmosphere of traditional Lingnan (Cantonese) culture for tourism development. This strategy has advantages for material recycle, construction energy saving and environmental protection, but arising an issue concerning heritage's authenticity. It is regarded that it must be adopted a cultural ecology's views to deal with the concept of authenticity especially in circumstance of heritage reuse with tourism exploitation.
\end{abstract}

Keywords. Lingnan impression park, heritage conservation, atmosphere-making, adapted reuse, authenticity

\section{Introduction}

Lingnan Impression Park is located at "Guangzhou Higher Education Mega Center". The Park was planned in 2003 as a waterfront culture place with Lingnan cultural characteristics. Over a decade development, it has become a window to learn the traditional Lingnan culture and a Guangzhou's suburban leisure destination. This article takes Lingnan Impression Park as case study to expound the strategies of cultural heritage conservation and adapted reuse. It is a practice of reconstruction and transformation of a traditional village into a successful tourism destination. The Park creates a traditional culture atmosphere to produce special tourism experience, also inevitably arises an issues concerning heritage authenticity.

\section{Transformation of Traditional Village into a Tourism Park}

In 2001, because of excellent location and environment, Xiaoguwei Island was selected as the site for the Guangzhou university town construction. The island has six aboriginal villages with rich traditional houses and cultural relics. So the governments decide to construct some museums to protect those cultural heritages in order to show

\footnotetext{
${ }^{1}$ Yifeng Wen, School of Architecture and Urban Planning, Guangzhou University, Guangzhou, 510006, China; E-mail: wenyifeng1968@sina.com.
} 
the University Town having rich cultural assets. Because nearby water with beautiful scenery and landscape, one village called Lianxi was picked out to conduct a renewal design for constructing a Guangzhou university town folk museum to display Lingnan (Cantonese) culture and also as a tourism attraction. Late the folk museum developed into a museum village as suburban leisure destination and taken over by a private enterprise renamed as Lingnan Impression Park in 2008.

Because of university town construction, some village's aboriginal residents were relocated at other places out the island, among of which the Liangxi village's residents were totally relocated especially for giving a room to constructing the Lingnan Impression Park. So the village was be emptied and lost its people and community.

In original Lianxi Village, in addition to some ancestral temples and traditional folk houses, there also have new residential houses built in recent years with two to five stories high, as seen in figure 1 . Because of not meeting the requirements of heritage protection planning and conflict with the traditional village style, they are demolished and replaced by archaism building. The principle in the reconstruction of Lianxi Village is to follow the original village spatial context as most as possible; the original natural landscape and village layout are the key elements to truly reflect the traditional village culture in Lingnan areas. The focus of transformation and upgrading of traditional village into a museum village and a tourism destination are adjusting original functional structure and making a new spatial system to adapt to new contents and activities [1].

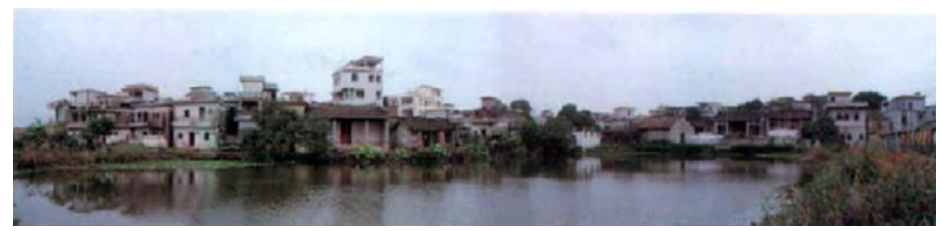

Figure 1. The original appearance of Lianxi Village.

Photo Source: Protection and Function transformation of Lingnan Traditional Settlement - Conservation and Renewal Design of Guangzhou University Town Folk Museum Village, Liao Zhi, 2008.

\section{The Value of Heritage and Reuse}

Because of putting economic pursuits first at the cost of heritage resources and vernacular cultural identities, urban heritage management in China has been criticized by international scholars as an unorthodox approach [2]. Despites of those criticisms, it is now appearing a shift of paradigm, and more innovative approaches and practices were arising. The underlying argument is that beyond previous concerning heritage authenticity, especially physical one, there is paying more attention to value of heritage adaptive reuse and living culture of heritage. Nonetheless, even due to the shifting focus from the materiality of heritage to its role in living culture and sustainable development, there is still with increasing attention on the role played by local communities, particularly in a cultural ecological view and emic perspective scope.

Cultural place and historic sites actively used are valued higher than those simply protected. The essential of adapted reuse heritage is that the discourse of heritage in sustainable way via participatory practices considerate of the specific social reality of China. With regard to architectural heritages and the concept of authenticity, there are 
two main theoretical approaches to assess where the value of a building or any cultural good comes from: one can be defined as extrinsic, meaning that value is detached from the material and only created by the society that uses it, or another one as intrinsic, meaning that value is inherent to the material fabric of the heritage [3]. In the case of Lingnan Impression Park, it is a practice of adapted reusing architectural heritage by reconstruction of old village based on its original layout and pattern, to adopt a strategy of architectural heritage reuse combined three modes: 1) heritage original site protection, 2) relocation and reconstruction of heritage/historic buildings, and 3) building new archaism architecture; the aim of which is produced a traditional Lingnan (Cantonese) Culture atmosphere for creating special tourism experience, meanwhile protecting some valuable folk architectural heritages existed in Guangzhou university town including those cultural assets that previously have been in other villages now relocated into the Park, as seen in figure 2 .
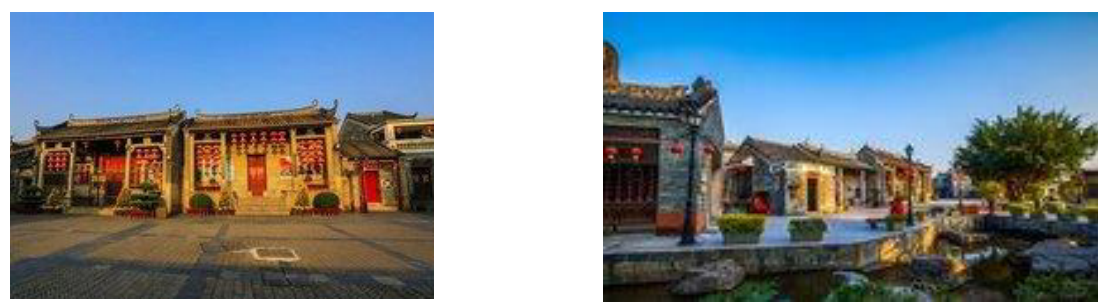

Figure 2. Ancestral temple as heritage in the Park or relocated in the Park.

This combined strategy inescapably arise an issue about heritage's authenticity. The concept of authenticity has been rousingly discussed from the second half of the 20th century onward. The concept of authenticity underwent an important evolution. Despite of strong efforts to adopt this concept as a tool / value for managing heritage, there has been considerable confusion around it, and it is to serve as a stimulus for arising discussion, or as a catalyst for opening up the debate. It is gradually discovered that based on material authenticity, object-centric logic to handle with dynamic, complex situation in cultural heritage conservation, has proven difficult. Objective authenticity-according to some scholars its meaning doubtful, is not because they are things inherently authentic, but is meant the result of social construction to form it; so the subjective/ existential authenticity is an alternative conceptual source to comprehensively understand the heritage's value [4]. If heritage "is not a 'thing", or not only as a objects, but rather a cultural and social practice through which items, sites, places, or practices and customs rooted in the past/tradition are endowed with meaning, then the heritage conservation will not be limited in maintenance or interventions of heritage's material fabric, but depend on deep understanding of heritage values, especially associated with how do we understand the concept of "authenticity". The authenticity as determined criterion for assessment of heritage's value was not only related with tangible heritage, also referred to Intangible Cultural Heritage. Moreover, the concept of authenticity holds a position of being the subject of cultural/heritage tourism, accepted to be a travel motivator in travel experience. The notion of authenticity experienced by tourists, or even in vast general people, according to many tourism studies, is differently from the heritage expertise; perceived authenticity (not so much of objective/physical one), or subjective authenticity which directly related with tourism experience are appreciated by tourists, and historical atmosphere is one of the 
most important factors to produce those associated effects. Based on this theoretical setting, it will be better prepared for discussions about what courses of action should be taken for the restoration of historic buildings in the context of cultural heritage conservation and reuse on a broad horizon.

"Atmosphere" as an aesthetic concept, according to phenomenological thought, it describes how subjects become enfolded by the built environment and experiences it as a nebulous state and an ephemeral "halfthing" belonging neither to the subject nor to the object [5]. Affective atmospheres is produced by through the situated assembly of human perceptual capacities and nonhuman actors - namely space, place and the built environment [6, 7]-creating a dynamic interplay in the generation of affects. Atmosphere is aesthetic aura shining a sensory light on place and animating people's spirit. Based upon these conceptual foundations, we can assess heritage value in a more comprehensive way in a context of tourism development and tourist experience. Considering that the Park has a actively function to enhance the cultural peculiarities of the Lingnan areas and respecting the material and spiritual reality of the architectural attributions of Cantonese, the Park construction is scheme connects and interrelates divergent practices that share strategies with regard to attuning to Lingnan cultural atmospheres, and addition to tourism's economic benefits, is also having social benefits - good for produce cultural identities by memory-making via historical imaginations.

For achieving the aim of creating Lingnan cultural atmosphere, except of reusing historical buildings and constructing some new archaism architectures, there are adopting other relevant design strategies to attain this end. The spatial pattern of Lianxi Village is composited by streets, alleys and courtyards. Based on reusing those spaces, tourism commercial activities were introduced with different themes according to various spatial features to create interest place and form special traditional commercial atmosphere. The style of architectures, the pattern and scale of streets, and the distribution characteristics of business are key elements for succeed in making traditional place feeling. This exploitation strategy also has advantages in material recycling, construction energy saving and environmental protection because of reusing some architectural heritage and keeping original landscape with little change in tune with the principle of environmentally-friendly design, as shown in figure 3.

The success of Lingnan Impression Park lies not only in its traditional architecture style and appearance, but more importantly in its combination of material cultural assets with intangible cultural heritage in process of tourism management. Taking full advantage of the place spirit of original Lianxi Village with synergy of many Cantonese cultural elements, it shows a strong Lingnan impression to tourists in an allround and multi-angle way. Through introducing the folk custom activities including those existed in other villages in Xiaoguwei Island as representation of Cantonese intangible cultural heritage, it forms syncretic effects for creating the cultural theme of "Lingnan Impression". Visitors can feel the colorful Lingnan intangible culture such as paper-cutting, oil-extracting exhibition, folk custom performance and with other participatory activities to produce charm experience of tourism. By means of "social choreography" [8] and the organization of spatial relationalities in urban encounters [9], forming new tourism communities, it is turned objects of built environment, the everyday perception of bodies and their activity into tourism subjective authentic experience. This practice can offset some shortages in heritage protection produced by empty of aboriginal village through creating a new participatory community and forming a new cultural ecology around heritage reuse. 

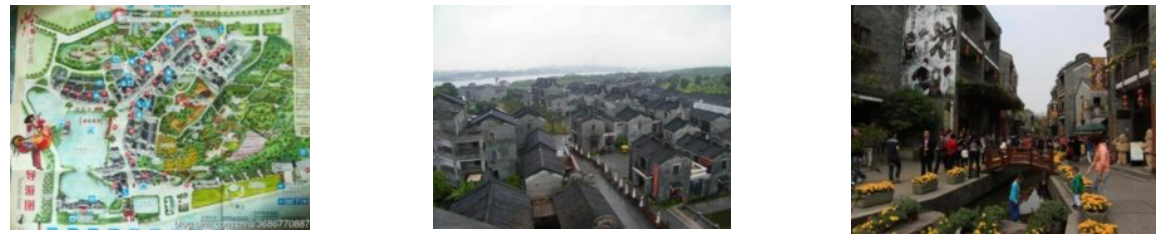

Figure 3. The Lingnan Impression Park.

Discussion the issues of heritage conservation in terms of cultural ecology, first we should recognize the heritage as living things that should be adapted to their existed environment, which means, in heritage conservation and adaptive reuse, all adaptations are constantly adjust to local conditions. Therefore, it is unreasonable to situate the heritage outside of the environment and cultural context with regard to both economic and social concerns. Given the relationship of culture and environment is an ongoing process, it should adopt a dynamic way to make decisions about how to achieve planning goals in complex heritage preservation projection. For the Lingnan Impression Park, the good atmosphere produced by renewal construction indicates cultural ecological vitality existed in the Park created by synergetic effects of combining landscape, architectural heritage and tourism authentic experience. All of those elements in a cultural ecological system work together to form a virtuous cycle of cultural energy around the heritage conservation and adaptive reusing, so the projection of Lingnan Impression Park indicates that it is "do a good job" in terms of its fully adaptive using heritage value in a sustainable/cultural ecological way.

\section{Conclusions and Prospects}

The Lingnan Impression Park as a success of tourism projection with cultural conservation depends on its resources of natural landscape like mountains, water and so on around the village, also on historical buildings and cultural assets. In addition to those, the proper operation in manage the Park is important. In the beginning, the reconstructed Lianxi village defined as university town folk museum was directly operated by government, which results expenditure exceeding income. In 2008, the government adjusted its position and discussed the possibility of developing tourism industry, and finally decided to lease the Folk Museum to a Guangzhou travel company and renamed it as Lingnan Impression Park. This case can show that a market economy can provide more effective manner to efficiently exploitation of resource, which results the Lingnan Impressions Park having been developed into a mature tourist attraction and won the favor of tourists.

The Lingnan Impressions Park highlight the theme of reusing historic buildings, it shows that the huge number of abandoned or underused buildings, especially to those historic architectures, can become a driving force for urban regeneration and for pursuing sustainable urban development [10]. This promotes local government to evaluate possible investments in advance and support entrepreneurship through innovative ways of business operation triggering economic development processes, to raise the quality of cultural offer both for local and tourist. Bearing this in mind, because of Pandemic of 2019 and its limitation for tourism, the Park was temporarily closed for new reconstruction to integrate more elements for new development, 
including a new hotel constructed by-side, as shown in figure 4, which will give a good case for further studying a comprehensive issue of heritage conservation and reuse, as well as about the complex concept of authenticity in perspective of cultural ecology in heritage tourism setting. Authenticity is a humanism term and a value, so we should not be limited it in the physical scope and objective meaning, but understanding it in the subjective and existentialism connotation. In the view of cultural ecology and tourism context, "atmosphere making" is essential for creating tourist subjective authenticity, also as one of the most important aims for heritage conservation.
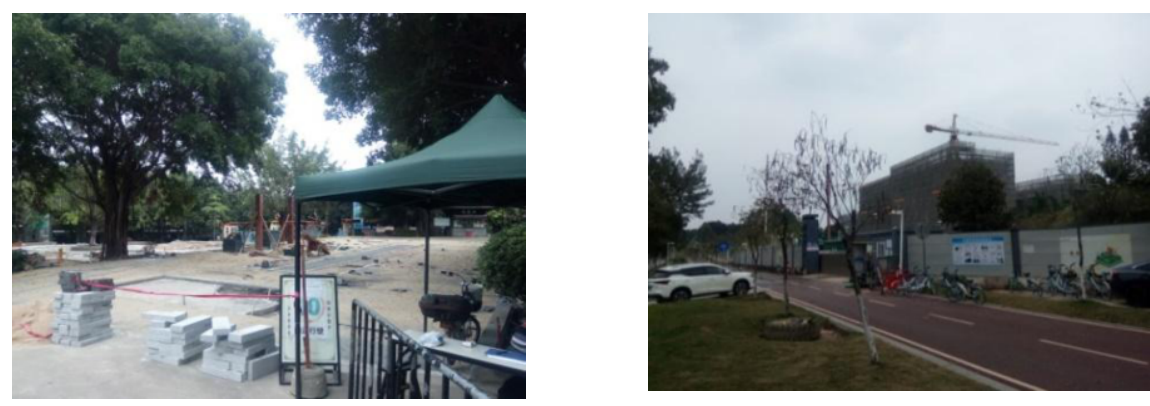

Figure 4. New reconstruction of the Park and by-side hotel.

\section{References}

[1] Liao Z and Lu Q. Reconstruction and renewal of lianxi ancient village in xiaoguwei island: design of folk and naturalistic village of Guangzhou University Town. Huazhong Architecture. 2008; 8: 177-181.

[2] Verdini G, Frassoldati F \& Nolf C. Reframing China's heritage conservation discourse Learning by testing civic engagement tools in a historic rural village. International Journal of Heritage Studies. 2017; 23(4): 317-334.

[3] Bucher B \& Kolbitsch A. Coming to terms with value: Heritage policy in Vienna. HERITAGE \& SOCIETY. 2019; 12(1): 41-56.

[4] Wang N. Rethinking authenticity in tourism experience. Annals of Tourism Research. 1999; 26(2): 349-370.

[5] Göbel HK. Making cultural values out of urban ruins: Re-enactments of atmospheres. Space and Culture. 2021; 00(0): 1-13.

[6] Göbel HK. The re-use of ruins: atmospheric inquiries of the city. Routledge; 2015.

[7] Sumartojo S \& Pink S. Atmospheres and the experiential world. Theory and methods. Routledge; 2019.

[8] Klein G. Urban choreographies. Artistic intervention and the politics of urban space. In R. Kowal M Randy \& Siegmund G (Eds.). The Oxford handbook of dance and politics, Oxford University Press; 2017. p. 131-148;

[9] Pusca A. Industrial and human ruins of postcommunist. Europe Space and Culture. 2010; 13(3): 239255.

[10] Spina LD. Cultural heritage: A hybrid framework for ranking adaptive reuse strategies. Buildings. 2021; 132(11): 1-23. 